\title{
Emphysematous Cholecystitis
}

National Cancer Institute

\section{Source}

National Cancer Institute. Emphysematous Cholecystitis. NCI Thesaurus. Code C35592.

Cholecystitis resulting from infection by gas producing organisms. 